\title{
CLEARING SNOW FROM RAILWAY TRACKS IN CANADA.
}

The accompanying illustrations show the construction and operation of a novel cylinder snow plow de signed and constructed in the Province of Ontario. When the plow of this remarkable machine is forced into a drift or cut, the snow is lifted by the shovel, which is inclined upward and meets the expeller chambers, the snow gliding along until it comes in contact with the expellers, the blades of which revolve at a high speed, in an upward direction. Engaging the snow, the blades throw it upward and outward at a rew, the blades throw it upward and outward at a feet on each side of the plow and making a clear cut, 11 feet in width, and at a speed of 6 to 8 miles per hour in a cut 10 feet deep. The snow is elevated and thrown at so great a distance from the track, the possibility of the smallest quantity ever getting into the cut again is precluded. The snow does not enter the exmaximum velocity of the expeller blade at the periphery is 5,654 feet.

The accompanying illustrations are front and side views of this remarkable cylinder snow plow. In one view the snow expellers are shown in operation; in another a cut 12 feet deep is illustrated. The reader will doubtless note the impression which wedge doubtless note and apron leave on the snow. The thin end projects only 20 inches ahead of the expeller. Other illustrations show the cleaned track in a ten-foot cut, and the machinery within the plow car, including the boiler steam pipes and engine. The expellers are directly connected with the engine shaft by means of two steel chain belts.

It is stated that each of the steel chain belts driven by the steam engine of this plow is capable of driving the expellers at a moderate speed alone, so that should one belt be disabled the plow would still be able to work at a somewhat lower rate of speed.

The plow body is of steel construction throughout the box portion having the sides covered with wood like a box car. The roof is of similar construction, which is fire and water-proof. A door is provided on each side in the middle of the car, the back end bein left open for convenience in stoking the boiler. A lookout is built at the front end of the car from which point the engineers can be signalled to.

The front end of the car, entirely of steel, has thre chambers, the two side ones being circular, open at the front and one side, in which the expellers revolve. These are nine feet in diameter and three feet six inches wide. Each expeller consists of a cast iro hub, upon which are formed four spiral flanges, having a pitch of about fourteen feet. Riveted to these flanges are four half-inch steel plates or blades twentytwo inches wide, comprising a true helix upon the hub. The expellers are mounted upon each end of the shaft and overhang the pedestals, the shaft extending into the circular chambers. On the middle of the shaft, which is eight inches in diameter, is keyed the sprocket wheel, which is connected with a similar wheel on the shaft of the engine by the steel chains. These four parts constitute the drive gear. The mid dle chamber opens to the interior of the car. On the front is constructed the nose of the plow, consistin of steel plates projecting forward to the end of the apron or shovel. It may be stated that the apron or

\section{B Y FRANK C. PERKINS.}

shovel is attached to the bottom framing, the side plates, the interior web plates, and the expeller cham bers, by steel angles and plates. This apron extends forward five feet beyond the center of the expellers present a rigid construction to engage the snow.

This powerful cylindrical snow plow has engine specially constructed. The cylinders are sixtee inches diameter with eighteen-inch stroke and work under a steam pressure of 150 pounds per square inch, the maximum speed being two hundred revolutions er minute. Ther are capable of developing 750 Ii $H$. $P$. The nose and shovel, being firmly riveted together, and are placed as near as possible to the expellers

with a solution of potash waterglass. Sometimes. a repetition of this process will be necessary to thoroughly fill all the pores of the stone. It is enough if the stone is saturated to a depth of about $1 / 2$ inch. Whitish brush marks may be cleaned either by rubWing with a piece of the same stone, or by refacing the stone, or by brushing with steel brushes. Should the solution not impregnate the stone quick enough, it must be diluted with more water. The solution should be entirely absorbed by the stone in about one minute. Whatever is left over on the surface the crystals formed by the evaporation of the water would make a rubbing and cleaning of the stone necessary. A separate brush should be used for each solution, so that the reaction should begin in the pores of the stone. For larger surfaces atomizers or sprinklers may be used successfully.

Through these processes any soft limestone or sandstone may be made more compact and hard. Their porousness and im perviousness will equal that of the hardest stone. After treatment they may be polished and cut. The great advantages of the soft stones-cheapness of quarrying and cutting-remain, and they can receive afterward all the prominent qualities of the harder stones.

Mortar and concrete may also be hardened and compacted by these processes, so that they may be used with greater success in works calling for water-tightness, as water works, tanks, street pavements, sidewalks, artificial stone, cement blocks, etc.

Monuments can also be protected by these processes from the influence of the weather.

Process of Removing Hair from Hides.

An article in the Ledertechnische Rund-
A view showing an expeller.

to shorten the drive chain. The engines exhaust into the bottom of the smoke box of the boiler through a suitable nozzle, similar to locomotive practice, creating a strong blast.

\section{Hardening of Soft stone.}

Mr. A. Kubelka of Bushowitz in Morairu has discovered a process by means of which the softest sandstone or limestone can be made hard. The process is the following: First, the surface of the stone must be thoroughly cleaned, so as to expose the pores. Any oil or grease spots must be removed with benzine or with the alcohol flame. Missing pieces must be filled up with cement mortar, using a 1:7 solution of waterglass for tempering. After the stone is thoroughly dry, it is saturated with a solution of potash or soda waterglass. In case of rain during or immediately after this operation, the stone must be again cleaned, dried, and saturated with the solution. Then follows an impregnation with molten chloride of calcium. After this impregnation rain will do no more harm, as on account of the reaction of the chloride of cal cium upon the solution of waterglass, the pores of the stone will be filled with insoluble, hard silicate of lime, while the soluble silicate of lime will be decomposed and washed out by rain. Another method of Kubelka's is to saturate the stone first with a solution of sulphate of alumina, in water, and when dry schau mentions, without describing in detail, a new process for the removal of hair from hides, in which the agents commonly employed for this purpose (lime, sodium sulphide, etc.) are replaced by "a suitable gas," which effects the removal of the hair in from two to eight hours. The process is said to be especially valuable for the preparation of colored leather, and fine leather in general, as the product is of very uniform grain and free from the spots which are often produced by lime and sodium sulphide. The leather is also much closer, tougher, stronger, and more flexible than leather made by the usual methods. Hides treated by the new process may be tanned with bark, extract, or chrome alum. The inventor, whose address may be obtained from the journal quoted, will furnish detailed information to persons interested.

The Coming Aeronautic Show at Boston

The first Aeronautic Show to be held in the United States without connection with any other exhibition, will open in Mechanics Building, Boston, Mass., on February 16th, and not on the 23rd, as announced in our last issue. This show will remain open one week. Seventeen full-sized aeroplanes have already been secured, and the exhibition promises to be a representative one as far as the heavier-than-air machines are concerned. The manager can be addressed at 5 Park Square, Boston, by any experimenters having machines to exhibit.

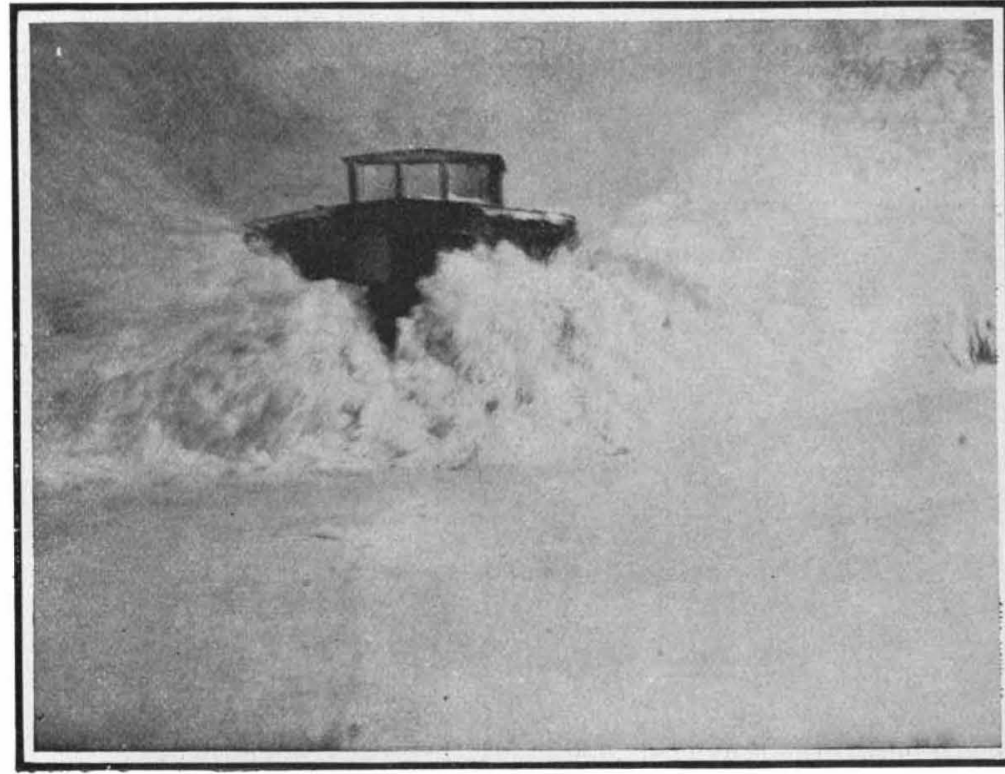

The plow in operation.

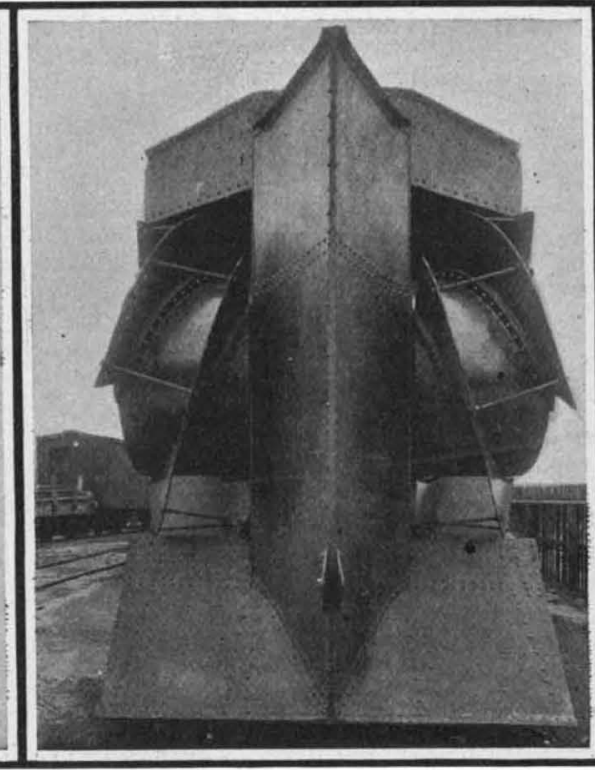

Front view of plow.

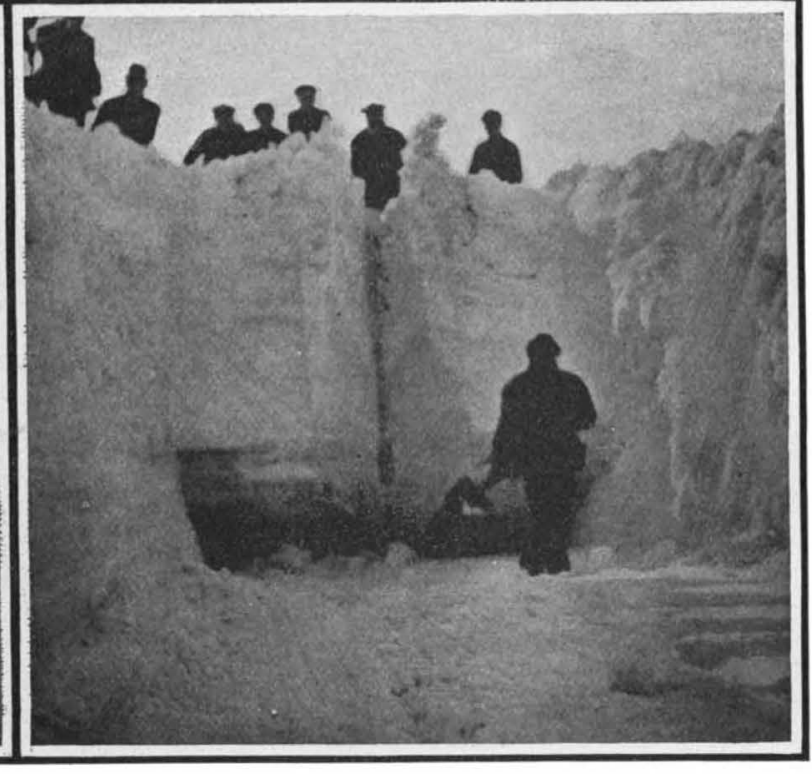

Plow withdrawn to show nature of ent. 